\title{
GCU
}

Glasgow Caledonian

University

University for the Common Good

\section{Measuring differences in living standards within households}

\section{Cantillon, Sara}

Published in:

Journal of Marriage and Family

DOI:

10.1111/jomf.12023

Publication date:

2013

Document Version

Author accepted manuscript

Link to publication in ResearchOnline

Citation for published version (Harvard):

Cantillon, S 2013, 'Measuring differences in living standards within households', Journal of Marriage and Family, vol. 75, no. 3, pp. 598-610. https://doi.org/10.1111/jomf.12023

\section{General rights}

Copyright and moral rights for the publications made accessible in the public portal are retained by the authors and/or other copyright owners and it is a condition of accessing publications that users recognise and abide by the legal requirements associated with these rights.

Take down policy

If you believe that this document breaches copyright please view our takedown policy at https://edshare.gcu.ac.uk/id/eprint/5179 for details of how to contact us. 


\title{
Measuring Differences in Living Standards Within Households
}

Sara Cantillon ${ }^{*}$

DOI: $10.1111 /$ jomf.12023

Copyright (C) National Council on Family Relations, 2013

Volume 75, Issue 3, pages 598-610, June 2013

\section{Keywords:}

- consumption;

- gender;

- independent income;

- intrahousehold;

- nonmonetary indicators;

- poverty

\begin{abstract}
This article presents a quantitative approach used to investigate differences in living standards between spouses within households. Adopting a specially adapted, standard poverty measurement approach - nonmonetary indicators - it explores differences between spouses in terms of possessions and access to certain goods and services and the control and management of household resources. Using data from a unique module in the Living in Ireland Survey ( $\mathrm{N}=2,248$ individuals) as an exemplar, the article focuses on 3 methodological issues: (a) the development of specially designed nonmonetary indicators to explore differences in living standards within households rather than between households (including the role played by qualitative findings in developing those indicators and how focus groups were used to assess and validate the method), (b) the use of multivariate analysis to assess the impact of a wife's independent income in ameliorating differences in living standards between spouses, and (c) the deployment of a mechanism for use in quantitative surveys to record spousal presence and allow measurement of any subsequent difference in individual responses.
\end{abstract}

Conventional analysis of poverty and income inequality tends to neglect what goes on within households, with little attention paid to any differences among household members in living standards or in access to and control over resources. As the other articles in this special section of the Journal of Marriage and Family attest, the position of individual family members is therefore based on the situation of the household, with the assumption (explicit or implicit) of equal distribution of resources and equalization of living standards within households. The difficulties created by this assumption have been well demonstrated 
theoretically and empirically (Bonke \& Browning, 2009; Falkingham \& Baschieri, 2009; Lundberg, Pollak, \& Wales, 1997; Phipps \& Burton, 1995; Vogler \& Pahl, 1994; Woolley, 2003). The results show, unsurprisingly, that the assumption made about sharing can make a great deal of difference, particularly to the position of women and children. The crucial questions left open are just how much sharing actually does take place and, as a consequence, how great are the differences in living standards among individuals within a household. A number of different avenues of research have explored this empirically in industrialized countries (see Bennett, 2013). An alternative approach to assess the extent of differences in living standards within the household was used in an empirical study in Ireland. This involved the development of specially designed nonmonetary deprivation indicators, for adults and children, and of questions relating to the control and management of resources within households to specifically reflect differences in living standards within rather than between households.

The methodological approach described in this article focuses exclusively on the individual situation of heterosexual married couples with and without children. The methodology used combines concepts and tools from traditional and feminist, quantitative and qualitative fields of inquiry - it uses a conventional measurement approach (i.e., nonmonetary indicators) derived from the literature on poverty while at the same time rejecting the unitary household assumptions that traditionally underlie it, and it uses a large-scale quantitative approach, but one in which the selection of these specially designed indicators was explicitly informed by the findings of qualitative studies. This approach thus substantiated, at a nationally representative level, the findings of previous qualitative research and allowed quantitative analysis of previously identified areas of interest, such as the function of wives' independent incomes and the testing of these for statistical significance.

The focus of this article is the methodological design of an ad hoc module in the Living in Ireland Survey (LIIS; see http://www.ucd.ie.gcu.idm.oclc.org/issda/data/esri/livinginireland/), so the discussion of the data is used only as an illustration of the project's methodology. The Background section sets out the nonmonetary indicator approach, which is increasingly being used alongside income to measure household living standards across households. It highlights the limitations of this approach, as conventionally applied, in probing differences between individuals within households, while making the case for its potential in this regard. The Method section starts by outlining the approach to develop individual-level nonmonetary indicators. It reviews the process by which the new questionnaire and set of indicators were constructed, and it explains how focus group sessions were used as a means of assessing and validating the approach taken. The Results section begins by providing a selection of the results in relation to the nonmonetary indicators and differences in control and management of finances. It then addresses the determinants of those differences between spouses, focusing on the results for two specific variables issues: (a) the impact of a wife's independent income in reducing differences between spouses and (b) the impact of the presence of a spouse at an individual interview in terms of influencing the responses given.

\section{Background}

The starting point for the design and development of individual-level nonmonetary indicators was the limitations of quantitative data available for investigating differences within households. Nonmonetary indicators are often used as a complementary measure to relative income lines in measuring poverty. Relative income poverty lines show how a household income compares to the average or median income, whereas nonmonetary indicators take into 
account access to resources other than income. An index of items and activities that are generally considered representative of normal living standards in a particular society is compiled. People who are denied, through lack of resources, a certain number of the said items or activities are regarded as experiencing relative deprivation. There is ongoing debate in relation to nonmonetary indicators, the use of subjective assessments, and the issues that may arise in terms of how people might prioritize things other than what might be regarded as necessary to maintain a decent living standard (McKay, 2004). In terms of the inquiry here, however, which addresses differences between spouses, it seems reasonable that one might be concerned about those cases in which one spouse has the item and the other does not and says that this is because of lack of money.

Deployed within large-scale, primarily household-based, national surveys, nonmonetary indicators seek to elicit information on household financial practices and styles of living. Questionnaires are completed by what used to be called the "Head of Household" but is now referred to as the "Household Reference Person." The key point is that this one person responds on behalf of the whole household, and his or her answers are taken to reflect the situation of the household as a unit. The items that compile the nonmonetary indicator list thus naturally reflect a concern with a household standard of living rather than a focus on more individual or personal items or areas of consumption where gender differences are liable to be greatest. The emphasis is on items of family, or household, consumption rather than individual consumption - for example, the indicators used in the EU Survey of Income and Living Conditions (EU-SILC; Eurostat, 2011) or Breadline Britain (http://www.guardian.co.uk/society/series/breadline-britain) include replacing worn-out furniture or keeping the house warm. That is not to say that there is not a gender dimension to items of joint or household consumption such as access to and use of the car. For example, a number of qualitative studies have shown that the consumption of food, especially meat, is sensitive to gender differentiation (Charles \& Kerr, 1987; Delphy \& Leonard, 1992; Land, 1983). These suggest that the distribution of food within families reflects differences in the status of family members and that there is gender and age differentiation in both the quality and quantity of meat consumed. For example, Delphy (1984), in her study of farm workers in rural France, found that the distribution of food reflected the differences in status of family members, with high-quality foods, such as meat, reserved for the head of household. So, for example, husbands and wives may be more likely to differ on what kind of meat is eaten by various family members, rather than on whether there is a meal with meat every second day, as asked in standard household-level nonmonetary indicator questionnaires.

A related limitation of the conventional use of nonmonetary indicators approach concerns the fact that the indicators used for the most part reflect the living standards of individuals in poverty. Minimal clothing levels and eating patterns are emphasized, whereas items that are not so basic or that concern leisure or social activities are less well represented, because of the differences in the way in which these items and activities are attained. It is more likely that there will be differences in where individuals go and how much personal money they have to spend on social activities, rather than whether there is some access to these activities at the most basic level.

Another limitation of individual poverty data collected at the household level is the manner of its collection and the difficulties, created by the implicit assumption of equal sharing, in probing differences between spouses or indeed in uncovering previously (consciously or unconsciously) hidden areas of individual deprivation. 
To overcome these limitations of household-based surveys and to build on particular withinhousehold areas of interest indicated by qualitative research, we developed new indicators specifically to investigate individual levels of living within households in industrialized countries. The literature has not yet paid much attention to the potential of nonmonetary indicators designed to measure living standards at the level of the individual rather than the household that are suitable for use in quantitative surveys (Cantillon, Gannon, \& Nolan, $\underline{2004)}$.

\section{Method}

The development of these specially designed nonmonetary deprivation indicators and of questions relating to the control and management of resources within households to specifically reflect differences within rather than between households culminated in the inclusion of an ad hoc module in the nationally representative LIIS, which is used to monitor the evolution of poverty in Ireland. The LIIS formed the Irish component of the European Community Household Panel - a European Union-wide project, coordinated by Eurostat, now replaced by the EU Statistics on Income and Living Conditions. (The full questionnaire and the ad hoc module Section Q Partners-Material Outcomes are available in the Journal of Marriage and Family section of the Wiley Online Library; http://onlinelibrary.wiley.com.gcu.idm.oclc.org/journal/10.1111/[ISSN]1741-3737.) The LIIS is built around a core harmonized questionnaire, but stand-alone modules of questions to meet specific national data needs can be added on as required. This was the mechanism used to add the module containing the specially designed questions on the intrahousehold distribution of resources. The LIIS is designed to provide a representative sample of private households in Ireland, with the sample drawn from the electoral register using a two-stage stratified random sampling procedure. The LIIS for 1999 (the focus of this article) interviewed 5,451 individuals in 2,842 households and obtained an 84\% household response rate. The very high response rate is a reflection of the fact that the (cross-sectional) survey has been ongoing, on an annual basis, since 1994. The sample available for analysis in the context of a comparison of spouses comprises 1,124 couples (2,248 individuals) for which both adults individually responded to the questions in the special module attached to the LIIS.

The data from the LIIS special module comprise the only quantitative study of intrahousehold issues undertaken in Ireland to date. Even internationally, there are very few quantitative data sets exploring intrahousehold differences in material outcomes. In the United Kingdom, there have been a number of studies of intrahousehold living standards, but analysis remains primarily at the level of the household, supplemented by some limited individual-level data (Adelman, Ashworth, \& Middleton, 2000; Gordon et al., 2000). A similar exercise, which comprised a data set of 500 individuals who were interviewed on a face-to-face basis in 1996, was undertaken in Sweden. The study was carried out as a supplementary project of Statistic Sweden's Annual Survey of Living Conditions. Like the Irish study, it attempted to compare the living standards of partners by consumption and nonmonetary indicators, including access to personal spending money, to determine the extent of within-household gender inequalities (Nyman, 1999).

Development of the nonmonetary indicators for the LIIS module involved combining the lessons drawn from earlier analysis of large-scale survey data with insights derived from small-scale qualitative studies as discussed above (Cantillon \& Nolan, 1998, 2001; Dodson, 2005). Another essential part of the exercise of developing suitable indicators was to get some "on the ground" feedback. A number of focus group sessions were organized to 
examine the potential of this general approach to assessing intrahousehold differences. The value of using qualitative inputs at this stage of the research was significant. The focus groups were drawn from training courses within two community development projects in Dublin City. The state-funded Community Development Programme financed a network of projects and organizations in communities experiencing economic and social disadvantage. Given that these were already-established groups (the members of which trusted one another and who were willing to talk as a group) made it much easier both to establish contact and to obtain their agreement to participate in the focus group exercise. The reflections by members of the focus groups on their experiences and the dialogue in the sessions were very useful, and their suggested changes were incorporated into the final questionnaire. For example, in talking about who manages the household finances or makes big financial decisions, a number of participants commented that the questions needed to be very specific if all the answers were not to be "we both do." Following on the focus group discussion, we broke a number of the questions on financial management into specifics, such as, "Do you pay the utility bills?", "Do you save?", "Do you buy the groceries?" Each of the questions was going to be asked at individual rather than household level. In addition, we added secondary specific questions to positive responses, so, for example, if the answer was "yes" to the question "Did you have to buy second-hand clothes in the last year?" the secondary question was "Was this for yourself, your spouse, [or] your children?"

Another key issue that arose in the focus groups was how to phrase the questions so as to ensure that the respondent understood that they related to his or her own individual consumption, rather than that of the household as a whole, and answered accordingly. This concern was particularly stressed in relation to leisure and social activities and to personal spending money. The focus group exercise supported the belief that the issue of differences in within-household living standards and differences in financial responsibility and control needed to be examined, rather than assumed a priori, and that the use of a Household Reference Person in most questionnaire sometimes obscured the situation of individual household members. The issue was raised concerning control of money and independent income, as opposed to household income however fully shared; this is discussed below. The focus groups also underscored the difficulties of developing appropriate indicators and in particular in framing the questions so as to ascertain the extent of such intrahousehold differences in the context of marital relations where outwardly, at least, the rhetoric of equality dominates. In this regard, the sessions underscored the sensitivity required in framing and posing questions relating to the distribution of intrahousehold resources and suggested that separate individual interviews with husbands and wives should be conducted. In the LIIS study each individual was interviewed separately, but it was not possible to ensure that the other spouse was not present, or in the vicinity, during the interview. The method used to record this and the possible impact of the spouse's presence on responses, together with the adjustment process, is discussed in the Results section.

\section{Developing Nonmonetary Indicators}

Three separate areas of investigation were chosen: (a) differences between adults in relation to consumption of goods and services; (b) differences in access to leisure and social activities, personal spending money, and education and training; and (c) differences in the control and management of financial resources. Although the indicators focused primarily on individual access to or consumption of goods and services and more on personal rather than household items or activities, they also included some familial or household-based items. The reason for this was that several small-scale studies had indicated gender differences in the 
way such items are distributed or consumed. Two indicators (using heating when it is cold and use of a car) were used as indicators of familial living standards that qualitative studies have suggested may be problematic in terms of assuming fairly equal access or consumption. Food consumption is another area identified as susceptible to gender differentiation, and particularly pertinent is the issue of self-denial, whereby an individual, usually the woman, "chooses" a smaller portion or none at all in situations when there is not enough for everyone. A number of questions and subquestions were included in the LIIS special module on food consumption that aimed to capture some of these nuances. For example, it asked: "Does the whole family usually have the same meal?" If the answer was "no," the respondent was asked, "Is that because of lack of money?" If he or she replied "yes," then it asked "Who has the less costly meal?" And separately, it asked "Do you ever find yourself skimping on your own meal so the rest of the family can have enough?"

The second area of investigation was social and leisure activities, an area in which previous studies, both qualitative and quantitative, have shown considerable differences between husbands and wives (Cantillon \& Nolan, 1998; Nyman, 1999; Rottman, 1994). Free time and personal spending money are considered significant factors in differences between spouses, with lower amounts of both acting as a constraint on women's leisure activities. Of particular interest is the idea that money may not be the key constraint when examining enforced lack. This is in contrast to some approaches to measuring household poverty using nonmonetary indicators, in which enforced lack (i.e., not having a particular item/activity because of a lack of money) is the central criterion for distinguishing between those counted as being or not being in poverty. The question on social activities was approached in a number of ways, asking each spouse separately about social activities and the amount of money spent on the activity as well as the availability of personal spending money and the sums involved. The aim was to investigate the possibility of how constraints other than money might curtail participation in activities outside the home.

From a methodological point of view, broadening the nonmonetary indicator question to capture "enforced lack" by constraints other than money allows a fuller picture to emerge that can complement and substantiate, in large-scale surveys, the gender differences found in the proliferation and increasing sophistication of time use studies (Bittmann \& Pixley, 1998; Burchardt, 2008; Fisher, 2011; Gershuny, 2012; Vickery, 1977).

The first two areas of investigation - differences (a) in material living standards and (b) in access to leisure/social activities - focused on outcomes. The third area focused particular attention on processes (Jenkins, 1994); it addressed the issue of management of household income, distinguishing in particular between control and management of finances within households (Heimdal \& Houseknecht, 2003; Yodanis \& Lauer, 2007). Differences in control over household finances are important in their own right, as an indicator of power, and in terms of the function they may play in producing and explaining differences in living standards. Differences in management are important insofar as they reflect men's and women's respective roles in decision making and, particularly at lower income levels, identify who carries the burden of responsibility for making scarce resources stretch. Several studies, using both small-scale surveys (Pahl, 1983, 1989) and large, nationally representative samples (Vogler \& Pahl, 1994; Yodanis \& Lauer, 2007), have explored different allocative systems for managing household resources and their implications for the living standards of individual members. The focus in this study was on the relationship between management and control of finances and patterns of spending within the household. Specifically, the interest was in examining the proposition that women in low-income households have the 
added burden of responsibility for making scarce resources stretch-what we term the burden of coping. To this end, we included the question: "When money is tight, who takes the main responsibility for trying to make sure it stretches as far as possible from week to week?"

In total, there were 20 nonmonetary indicators to which individuals responded on a yes-or-no basis: questions in relation to car use and heating, questions about food consumption, questions about social activities and personal spending money, and a further series of questions and subquestions on issues relating to the third area of investigation-household budgeting and management of financial resources.

If either a husband or a wife said that they did not have one of these items or participate in a particular activity, they were then asked whether this was because they did not want it or because they could not afford it. From this were compiled a variety of summary indices of indicators, separating the different areas of consumption and social activity with each item weighted equally. A summary index for husbands and for wives was compiled that reflected enforced lack, that is, a score was added to the index for each item lacked. (Note that it is important when constructing scales of this kind to determine how well the set of items measures a single construct. One such measure is Cronbach's alpha coefficient of reliability or consistency in the data. Cronbach's alpha for the male summary index is measured at .75, for the female index at .77, and for the combined index at .86, all of which indicate a high degree of consistency across these items.)

In using an approach that measures poverty at the level of the household via nonmonetary indicators, a threshold of more than two items is often used as a cutoff for identifying deprivation. We did not use this threshold here because we were measuring differences in living standards between spouses rather than interhousehold differences, and we also wanted to explore the differences across the income distribution rather than just focusing on those below a certain relative income poverty line. What we were measuring was not so much deprivation in the traditional sense used in the poverty literature-although it does encompass that - but rather the idea of being deprived of an item or activity relative to one's spouse's possession or enjoyment of that item or activity. In relation to household financial activity, we constructed separate summary measures of the burden of financial management and responsibility that related to budgeting decisions and sole financial responsibility, in particular in situations of scarce resources. We examined how these were distributed between partners, their movement across income poverty lines, and the relationship between these summary measures decision-making processes and a variety of socioeconomic variables. Finally, we constructed a measure of the difference between spouses by subtracting the husband's score on the summary index from that of the wife. A positive "gap" measure for the couple thus means that the wife has reported a higher level of "going without" than the husband, and a negative "gap" measure means the husband has reported a greater level of "going without."

\section{Results}

The analysis of the responses focused on the scale and nature of differences between spouses in living standards. The results showed, first, that the majority of husbands and wives reported that they did not have to do without these items because of a lack of money. This is consistent with the rapid increase in general living standards in Ireland that has been observed since the mid-1990s. Comparisons of the responses of partners revealed that these generally agreed. Where they disagreed, there was a consistent, albeit not very dramatic, imbalance in 
favor of husbands across all the items. There were minimal differences between husbands and wives in relation to use of heating or the car. In relation to food, the results showed that in $6.5 \%$ of all couples one spouse said that they skimped on meals. In about $4.5 \%$ of the 1,124 couples the woman skimped on her own meal to try to ensure that the rest of the family had enough and the man did not, whereas the reverse was true for $1.2 \%$ of the respondents. This finding is consistent with qualitative studies that have found not only that women were more likely to go without but also that this was implicitly sanctioned within a hegemonic family discourse in which the welfare of the children was seen as the primary responsibility of the woman and that normalized the idea that the woman should make sacrifices to this end (Goode, Callender, \& Lister, 1998). A recent study of food poverty in Ireland also found that about $7 \%$ of the population experienced "intense" food deprivation, with women being the most likely to do without (Dowler \& O'Connor, 2012).

The imbalance between husbands and wives widened, however, when the nonmonetary indicators broadened beyond the more basic items to areas of socializing practices, leisure activities, and personal spending money. Nearly $30 \%$ of couples gave different responses in relation to having a regular pastime or leisure activity, and in about two thirds of these it was the husband who had a regular leisure activity and the wife who did not have one. This contrasts with the findings of a qualitative study of 20 couples in Ireland that suggested that there was no real difference in the socializing practices of the couples interviewed, but this may have been influenced by the fact that they were all very-low-income households (Daly \& Leonard, 2002). The data set discussed here was instead composed of couples spread across the income distribution. In the LIIS module, a high proportion of the wives who did not have a leisure activity, whereas their husband did, cited lack of time (due to household or childcare responsibilities) rather than lack of money, as the reason. This same result held in relation to the "socializing" question, for which child care was given as the reason for not having had an afternoon or evening out over the previous fortnight by about $10 \%$ of wives and $3 \%$ of husbands. The results indicate, not surprisingly, that time - in particular, time spent on child care responsibilities - can be a greater constraint for women than money per se. The constraints of time and money are of a qualitatively different nature and are not simply exchangeable in the economic sense. With time as the constraint, and with the welfare of children viewed as the primary responsibility of the woman, it is not surprising that sacrifices to this end fell predominantly on the shoulders of the women in the sample who had children.

The findings on personal spending fit into the pattern established by previous national and international research showing that husbands were more likely than wives to have personal spending money and that, when they both had it, husbands had more to spend on themselves (Nyman, 1999; Pahl, 1989; Rottman, 1994; Vogler \& Pahl, 1994). The focus, however, has often been on families on welfare benefits, in and out of work, whereas this nationally representative study shows that the difference in personal spending money holds throughout the income distribution.

In relation to differences in access to and management of finances within Irish households, the general results are complex, with patterns varying not only across households but also across different areas of spending. On the whole, there was significant conformity in the answers given and a shared understanding about financial decision making and areas of responsibility. There were also differences; for example, when asked how they decide on purchasing a personal item such as a coat or a pair of shoes for themselves, the majority of both husbands and wives said they would buy the item straight away. There is, however, a 
difference between them, insofar as $61 \%$ of husbands, compared to $50 \%$ of wives, said that they would buy it straight away. Furthermore, $21 \%$ of wives, compared to $12 \%$ of husbands, said they would save for the item. The issue of control is explicit in the subquestion, which asked the respondents whether they would ask their spouse for money. The percentage of all respondents who said that they did so was fairly small, about $5 \%$ of the total sample, but nonetheless it is interesting to note that it was predominantly wives who asked their spouse for money $(4.5 \%)$ rather than husbands asking their wives $(1.5 \%)$.

Joint decision making was common among both low-income and other households for the purchase of most large household items, for borrowing and repaying money, and for dealing with large unexpected bills. A clear division in financial responsibility was evident, however, in relation to regular grocery shopping and weekly budgeting. The wife took on this role in more than half of sample couples, with most of the remainder saying that both partners did so. This may reflect the system within households for allocating resources (information on which was not collected) and the fact that, up until relatively recently, female labor force participation was low in Ireland by international standards, particularly for married women, suggesting a more traditional division of labor within the household.

In relation to the issue of managing scarce resources, the results suggest that this burden falls disproportionately on women. With regard to who takes the main responsibility for trying to ensure that money, when tight, stretches from week to week, the results show that it is seen as a joint responsibility in approximately $56 \%$ of couples and the sole responsibility of the wife in about $34 \%$ of the sample. In low-income households, that is, those below the $40 \%$ relative poverty line (median equivalized disposable income), joint responsibility and wives taking sole responsibility for making scarce resources stretch was split at around $46 \%$ each, respectively. This was replicated in the qualitative study in Ireland in which the authors found that the wife managed the money in 13 out of the 20 households (Daly \& Leonard, 2002). The novelty of this result is not the gender of who makes the money stretch, because this has been well documented, but rather that the same result is replicated in a large-scale survey, thus confirming and supporting the findings of small-scale studies, which are sometimes criticized with respect to how representative they are.

\section{Determinants of Differences Between Spouses: Wife's Independent Income}

A consistent theme of the literature on distribution of resources within the family is the role that the wife's own income can play in reducing differences between spouses, in improving her (and her family's) standard of living, and in increasing her implicit (or explicit) bargaining power (Cantillon \& Nolan, 1998; Goode et al., 1998; Pahl, 1989; Rake \& Jayatilaka, 2002; Yodanis \& Lauer, 2007). The results from the special LIIS module data substantiate the importance of economic independence for a wife. Crucially, they also demonstrate that it is the size of her independent income (from any source, excluding child benefit, a universal payment paid to all parents regardless of income to help with costs of raising children) that translates into discernible differences in relation to differences in living standards and in the burden of coping. (We excluded child benefit from the wife's income variable because, although it is usually paid to her, any impact it might have on the gap between husbands and wives on their nonmonetary indicator scores is indistinguishable from that of having children in the household, and in any case it is intended for the children rather than her.) 
Methodologically, a recognized advantage of quantitative rather than qualitative approaches is the potential to test the statistical significance of relationships. Through multivariate analysis, we were able to test the significance of a wife's income in ameliorating differences in within-household standards of living. As explained in the Method section, we began by constructing measures of the extent of the differences between spouses. We constructed several summary indices reflecting the different areas of inquiry. For the present purposes, we use just one summary deprivation index as the exemplar, that is, the four-item index for social activities (viz., a regular pastime or leisure activity, an afternoon or evening out for entertainment, personal spending money for pleasure or recreation, and educational/training pursuits). The summary index, reflecting enforced lack for these indicators, showed a gap (i.e., the difference between spouses) in scores for $29 \%$ of couples, with the wife reporting greater deprivation than her husband in $20 \%$ of these couples, compared to the $9 \%$ in which the husband reports greater deprivation.

An analysis of the data revealed that the mean gap between the wife's and the husband's index scores was consistently narrower when the wife had an income of her own, which was true for $66 \%$ of couples. The gap is narrower again for the $31 \%$ of couples in which the wife's income was greater than IR£100 per week. Table 1 describes how the mean gap between couples on the indices varies across the level of the wife's independent income. The wife's independent income is divided into three categories: (a) IR£0, (b) IR£0-100 ( $\approx 0-130$ USD) and (c) greater than IR£100 ( $\approx 130$ USD) per week. In all cases, the gap is positive.

Table 1. Gap Between Wife's and Husband's Scores by Wife's Income Level

Income

Mean gap

1. ${ }^{a}$

Note: IR£100 $\approx 130$ USD.

$0(n=385)$

$0-\operatorname{IR} 100(n=393)$

$>\operatorname{IR} 100(n=346)$

The mean gap (i.e., the difference between the husbands' and wives' scores for the four nonmonetary indicators) decreases as the wife's independent income increases, from .2 to 16 to .14 , as income increases from IR $£ 0$ to between IR 0 and IR 100 and to greater than IR£100 per week, respectively. In other words, the extent of the difference between husbands and wives in relation to social activities (viz., a regular pastime or leisure activity, an afternoon or evening out for entertainment, personal spending money for pleasure or recreation, educational/training pursuits) narrows with each increase in the wife's independent incomes.

Multivariate analysis substantiated the above cross-tabulation in that it showed a systematic relationship between the gap in male and female scores and certain household characteristics. The gap measure on enforced lack was taken as the dependent variable, and ordinary least squares regression was used to estimate the relationship between these and the independent variables in the left-hand column of Table 2 . In the full model all the independent variables are included, whereas the restricted model is produced by retaining only those variables that contribute to the explanatory power of the equation. The significance level criteria for entry and exclusion are set at .05 and .10 , respectively. In all cases, the $F$ statistic is statistically significant at the $1 \%$ level of significance; that is, the explanatory variables contribute 
significantly toward explaining variations in the dependent variables, notwithstanding the expected relatively low values of the associated $R^{2}$ value. In addition, for each of the restricted models, Ramsey's reset test failed to reject the null hypothesis that a linear functional form (as opposed to some nonlinear alternative) is appropriate at the $1 \%$ level.

Table 2. Determinants of Gap Between Wife's and Husband's Scores

\section{Enforced Lack}

\section{Variable}

\section{Constant}

Household income

Female has independent income

Age (husband $[\mathrm{H}]$; continuous)

Higher education $(\mathrm{H})$

Leaving cert. education $(\mathrm{H})$

Professional $(\mathrm{H})$

Skilled $(\mathrm{H})$

Employed (H)

Urban

Children

Adult present (at either interview)

$R^{2}$

$F p$

Breusch - Pagan test for heteroskedasticity $p$

Ramsey's reset test for functional form $p$
Full Model Restricted Model

$.6855 \underline{\mathrm{e}}(.2086) \quad .7390 \underline{\mathrm{e}}(.1930)$

$.0002(.0002) \quad .0002(.0002)$

$-.0005 \underline{\mathrm{e}}(.0002) \quad-.0005 \underline{\mathrm{e}}(.0002)$

$-.0096 \underline{\mathrm{e}}(.0025) \quad-.0097 \underline{\mathrm{e}}(.0024)$

$-.1820 \underline{\mathrm{e}}(.0573) \quad-.1815 \underline{\mathrm{e}}(.0520)$

$-.0965(.0612) \quad-.0990 \underline{\mathrm{c}}(.0601)$

$.0503(.0596)$

$.0593(.0631)$

$-.1320 \underline{c}(.0798) \quad-.1286 \underline{c}(.0781)$

$-.0021(.0497)$

$.1110 \underline{\mathrm{d}}(.0509) \quad .1104 \underline{\mathrm{d}}(.0403)$

$.0183(.0494)$

.0414

.0404

3.70 .0000

5.47 .0000

$229.13 .0000 \underline{b}$

$229.09 .0000 \underline{b}$

$3.98 .0078 \underline{b}$

$3.78 .0103 \underline{b}$

1. Note: ${ }^{a}$

Results are based on a four-item index, which focused on (a) a regular pastime or leisure activity, (b) an afternoon or evening out for entertainment, (c) personal spending money for pleasure or recreation, and (d) educational/training pursuits. Numbers in parentheses are White's robust standard errors. Household characteristics are associated with males unless otherwise indicated. cert. $=$ certificate equivalent of a

2 . U.S. high school diploma.

3.

Reject null hypothesis of homoskedasticity.

4.

$p<.10$.

5.

$p<.05$.

$p<.01$. 
The regression results showed that there is a negative relationship between a wife's independent income and the extent of the gap between husbands' and wives' scores, that is, the gap is narrowed. There is also a negative relationship between the age, education levels, and employment status of the husband and the extent of the gap between husbands' and wives' scores. Also of significance is the positive relationship between the presence of children and these gap measures; that is, with the presence of children, the gap between wives' and husbands' scores widens. This is consistent with the view that, to some extent, the wife gives up some of her own individual material well-being when children are present (Goode et al., 1998; Vogler \& Pahl, 1994). Indeed, the most recent work on child poverty in Ireland showed that $14 \%$ of children in deprived households are not themselves deprived based on child-specific nonmonetary deprivation indicators, suggesting a significant withinhousehold "protection" of children (Watson, Maitre, \& Whelan, 2012).

\section{Determinants of Differences Between Spouses: The Presence of a Third Party}

The third methodological issue in relation to quantitative surveys investigating intrahousehold issues concerns the actual circumstances of data collection and the impact of the presence of the other spouse, or third party. For example, in situations where every adult is interviewed (e.g., the UK Family Resources Survey; http://research.dwp.gov.uk/asd/frs/), this is usually done using the "parallel block" facility in the Blaise interviewing technology system, so that the interviewees (couple or family) are together answering the questions, with the interviewer switching through the questionnaire program screens from one respondent to the other, filling in the question answers. In this scenario, the interviewer is most unlikely to receive different answers to these questions, because invariably the question is discussed by the couple/family and an agreed-on answer provided. Many qualitative studies have shown that sensitivity and subtlety are required to tease out differences between spouses in activities and attitudes and that different answers are more common when the respondents are interviewed separately (Graham, 1987; Pahl, 1989). More specifically, such studies demonstrate that spouse presence may make it more difficult to reveal negative aspects of the marital relationship and may encourage respondents to provide answers that please their spouses. These studies, in a large and expanding literature, also cast doubt on the assumption that the answers of partners who are not interviewed separately represent the position of the individuals concerned (Anderson \& Silver, 1987; Aquilino, 1993; Boeije, 2004; Reuband, 2004).

As is the case in most quantitative surveys, we were not able, in carrying out the fieldwork for the LIIS special module, to ensure that each person was interviewed alone. In an effort to address this issue, interviewers were carefully instructed on the need for clarity about questions focusing on the individual's own situation versus that of the family or household situation. More significantly, interviewers were required to note, in a separate box designed specifically for this questionnaire, whether the partner or other adult family members were present when each respondent was completing the questionnaire. This approach has since been adopted in the UK Poverty and Social Exclusion Survey (http://www.bristol.ac.uk/sps/research) in which para data were collected to record whether the respondent was interviewed alone or whether another adult was present.

Our interest in the LIIS was to investigate whether the presence of a spouse at the interview might create problems in attempting to analyze individual data. Specifically, we wanted to test the concern, raised in relevant qualitative work, that responses on issues such as differences in living standards that might reflect badly on the respondent and/or the partner in 
some way would lead to the danger of inaccurate responses being provided. For example, it seemed less likely that a respondent would admit to skimping on food if the beneficiary of his or her selfless (or coerced) sacrifice is present.

First, we examined the extent to which another adult being present at the time of interview was influenced by household type, that is, by the specific characteristics of households, such as social class, education, geographical location, or income level. Against this background, we examined the presence of an additional adult at individual interviews on responses to both the nonmonetary indicators and the burden-of-coping measure (i.e., where one person takes sole responsibility for making scarce resources stretch). The results showed that the wife was more likely to give a positive response to a nonmonetary indicator question (i.e., she would say that she had the said item or activity) when another adult was present. The husband, on the other hand, was slightly more likely to give a negative response (i.e., he would say he did not have the said item or activity) when another adult was present. To determine whether this bias is statistically significant, we conducted a multivariate analysis that included the household factors that influenced the husband's score and the wife's score, as well as a control for the presence of another adult. In the case of the wife, the presence of a spouse had a statistically significant negative effect on the level of the index. This implies that, when a spouse was present at the time of the wife's interview, her reported deprivation scores were lower. In contrast, there was no statistically significant relationship between the presence of a spouse at the husband's interview and the reported deprivation.

In relation to our investigation into within-household financial management and responsibility, and in particular the "burden of coping," the results also showed a negative relationship, statistically significant at the $1 \%$ level, between the extent to which the burden of coping financially is acknowledged by the wife and the presence of the husband at the interview. This suggests that the wife was less likely to say that she carried the sole burden when the husband was there at the time of her interview. Again, however, the reverse was not the case; that is, the variable was not statistically significant for husbands when wives were present during the interview. These findings suggest that, when holding separate interviews on questions relating to living standards and intrahousehold financial activities, it is particularly important for wives that husbands are not present (Cantillon \& Newman, 2005). The results also show, however, that if it is not possible to ensure that participants are interviewed separately, as is frequently the case in large-scale national surveys, it is important to record spouse (and/or other third party) presence, which can allow for any bias to be tested and, perhaps, adjusted for, in the analysis of the results.

\section{Discussion}

Although the approach presented here is based on data gathered in Ireland, the methodology is clearly equally relevant outside the Irish context. The methodology used was an adaptation of a particular approach to measuring living standards at the level of the household to measuring them at the level of individual family members. It involved the design of specific, primarily individually based indicators to measure both material and social living standards and to investigate differences in access to and management of financial resources. The design of the questionnaire was explicitly informed and guided by the findings of qualitative approaches and refined through focus group discussions. The results indicate that differences in living standards between spouses within households, though evident, were not very substantial - at least, in relation to basic individual items or household items such as central heating, car use, and food consumption in general. On the other hand, however, significant 
differences in living standards between husbands and wives revealed themselves in relation to socialization practices, leisure activities, and amounts of personal spending money. In terms of differences in access to and management of finances within Irish households, the results showed a complex pattern whereby management arrangements varied not only across households but also across different areas of spending. In relation to the issue of managing scarce resources, the results suggest that this burden falls disproportionately on women.

The benefits of a quantitative approach were illustrated through testing some of the hypotheses generated from qualitative work: It allowed analysis of the results in relation to differences in living standards and in control and management of finances in the context of a large, nationally representative sample, thus confirming, for example, the well-documented gender differences found in qualitative work as to "who makes the money stretch," or how time can sometimes be more of a constraint than money. Multivariate analysis allowed exploration of the role of a wife's independent income in ameliorating within-household differences in living standards and financial responsibility.

This experience shows that carefully designed nonmonetary indicators in large-scale surveys provide a potentially fruitful approach to tackling sensitive and analytically difficult issues relating to the allocation and control of resources within the household. This is evidenced by the addition of an ad hoc module on intrahousehold living standards using a nonmonetary indicator approach to measuring living standards at an individual rather than household level in the EU SILC in 2010 (http://www.epp.eurostat.ec.europa.eu.gcu.idm.oclc.org). In addition, the approach can be used beyond spouses to include children and/or other members of a given household. For example, a nonmonetary deprivation approach using child-specific indicators was included as a special ad hoc module in the EU SILC 2009 (Eurostat, 2011). Most recently, the Poverty and Social Exclusion Survey of Britain (http://www.bristol.ac.uk/poverty/pse/) has, for the first time, adopted a nonmonetary indicator approach specifically at the individual level to explore differences in living standards within households. Further, the Poverty and Social Exclusion Survey 2012, a quantitative study, is accompanied by a parallel qualitative study, thus realizing the complementarities of the two approaches as advocated in this article.

\section{Note}

I extend many thanks to Fran Bennett for all her assistance.

\section{References}

- Adelman, L., Ashworth, K., \& Middleton, S. (2000). Intra household distribution of poverty and social exclusion: Poverty and Social Exclusion Survey of Britain. Working Paper No. 23. York, UK: Joseph Rowntree Foundation.

- Anderson, B., \& Silver, B. (1987). The validity of survey responses. Social Forces, 66, 537-554.

- Aquilino, W. (1993). Effects of spouse presence during the interview on survey responses concerning marriage. Public Opinion Quarterly, 57, 358-376.

- Bennett, F. (2013). Researching within-household distribution: Overview, developments, debates, and methodological challenges. Journal of Marriage and Family, 75, 582-597.

- Bittmann, M., \& Pixley, J. (1998). The double life of the family-Myth, hope and experience. St. Leonards, New South Wales, Australia: Allen \& Unwin. 
- Boeije, H. R. (2004). And then there were three. Field Methods, 16, 3-22. doi:10.1177/1525822XO3259228

- Bonke, J., \& Browning, M. (2009). The allocation of expenditures within the household: A new survey. Fiscal Studies, 30, 461-481.

- Burchardt, T. (2008). Time and income poverty. Case Report 57. York, UK: Joseph Rowntree Foundation.

- Cantillon, S., Gannon, B., \& Nolan, B. (2004). Sharing household resources: Learning from nonmonetary indicators. Dublin, UK: Institute for Public Administration.

- Cantillon, S., \& Newman, C. (2005). Bias in interview data created by third party. Radical Statistics, 90, 32-45.

- Cantillon, S., \& Nolan, B. (1998). Are married women more deprived than their husbands? Journal of Social Policy, 27, 151-171.

- Cantillon, S., \& Nolan, B. (2001). Poverty within households. Feminist Economics, 7, 5-23. doi:10.1080/135457001316854692

- Charles, N., \& Kerr, M. (1987). Just the way it is: Gender and age differences in family food consumption. In J. Brannen \& G. Wilson (Eds.), Give and take in families. London: Allen \& Unwin.

- Daly, M., \& Leonard, M. (2002). Against all odds-Family life on low income in Ireland. Dublin, UK: Institute of Public Administration.

- Delphy, C. (1984). Close to home. London: Hutchinson.

- Delphy, C., \& Leonard, D. (1992). Familiar exploitations: A new analysis of marriage in contemporary Western societies. Cambridge, UK: Polity Press.

- Dodson, L. (2005). Poor mothers and habits of hiding. Journal of Marriage and Family, 67, 949-959. doi:10.1111/j.1741-3737.2005.00186.x

- Dowler, E., \& O'Connor, D. (2012). Rights based approaches to addressing food poverty in Ireland and the UK. Social Science \& Medicine, 74, 44-51. doi:10.1016/j.socscimed.2011.08.036

- Eurostat. (2011). European Union Statistics on Income and Living Conditions (EUSILC). Retrieved from http://epp.eurostat.ec.europa.eu.gcu.idm.oclc.org/portal/page/portal/microdata/eu_sil c

- Falkingham, J., \& Baschieri, A. (2009). Gender and poverty: How we can be misled by the unitary model of household resources-An illustration from Tajikistan. Global Social Policy, 9, 43-62. doi:10.1177/1468018108100397

- Fisher, K. (2011). Expanding capacity to analyze time use data. Electronic Journal of Time Use Research, 8, 146-149.

- Gershuny, J. (2012). A method for estimating long-term time use from short diaries. Annales d'Economie et de Statostique, 105/106, 247-270.

- Goode, J., Callender, C., \& Lister, R. (1998). Purse or wallet: Gender inequalities and income distribution within families on benefit. Tyne, UK: Policy Studies Institute/Athenaeum Press.

- Gordon, D., Adelman, L., Ashworth, K., Bradshaw, J., Levitas, R., Middleton, S., Pantazis, C., Patsios, D., Payne, S., Townsend, P., \&Williams, J. (2000). Poverty and social exclusion in Britain. York, UK: Joseph Rowntree Foundation.

- Graham, H. (1987). Women's poverty and caring. In C. Glendinning \& J. Millar (Eds.), Women and poverty in Britain. Brighton, UK: Wheatsheaf.

- Heimdal, K., \& Houseknecht, S. (2003). Cohabiting and married couples' income organization: Approaches in Sweden and the United States. Journal of Marriage and Family, 65, 525-538. 
- Jenkins, S. (1994). The within household distribution and why it matters: An economist's perspective. Discussion paper. Swansea, UK: University College of Swansea.

- Land, H. (1983). Poverty and gender: The distribution of resources within the family. In M. Brown (Ed.), The structure of disadvantage. London: Heinemann.

- Lundberg, S., Pollak, R., \& Wales, T. (1997). Do husbands and wives pool their resources? Evidence from the UK child benefit. Journal of Human Resources, 32, 463-480.

- McKay, S. (2004). Poverty or preference: What do "consensual deprivation indicators" really mean? Fiscal Studies, 25, 201-223. doi:10.1111/j.1475$\underline{5890.2004 t b 00102 . x}$

- Nyman, C. (1999). Gender equality in the most equal country in the world? Money and marriage in Sweden. Sociological Review, 47, 766-793. doi:10.111/1467954x.00195

- Pahl, J. (1983). The allocation of money and the structuring of inequality within marriage. Sociological Review, 31, 235-262. doi:10.1111/1467-954X.ep5463195

- Pahl, J. (1989). Money and marriage. London: Macmillan.

- Phipps, S., \& Burton, P. (1995). Social/institutional variables and behavior within households: An empirical test using the Luxembourg Income Study. Feminist Economics, 1, 151-174.

- Rake, K., \& Jayatilaka, G. (2002). Home truths: An analysis of financial decisionmaking within the home. London: Fawcett.

- Reuband, K. (2004). On third persons in the interview situation and their impact on responses. International Journal of Public Opinion Research, 4, 274-269.

- Rottman, D. (1994). Income distribution within Irish households. Dublin, UK: Combat Poverty Agency.

- Vickery, C. (1977). The time poor-A new look at poverty. Journal of Human Resources, 12, 27-48.

- Vogler, C., \& Pahl, J. (1994). Money, power and inequality within marriage. Sociological Review, 42, 262-288. doi:10.1111/1467-954X.ep9407143246

- Watson, D., Maitre, B., \& C. Whelan (2012). Work and poverty in Ireland. Dublin, UK: ESRI.

- Woolley, F. (2003). Control over money in marriage. In S. A. Grossbard-Shechtman (Ed.), Marriage and the economy (pp. 105-128). Cambridge, UK: Cambridge University Press.

- Yodanis, C., \& Lauer, S. (2007). Managing money in marriage: Mutilevel and crossnational effects of the breadwinner role. Journal of Marriage and Family, 60, 13071325. doi:10.1111/j.1741-3737.2007.00449.x 